\title{
Opioid analgesics suppress male gonadal function, but opioid use in men and women does not correlate with symptoms of sexual dysfunction
}

\author{
Dana Wong BSc ${ }^{1}$, Dan Gray MD FRCPC ${ }^{2}$, Mark Simmonds MD FRCPC ${ }^{2}$, Saifee Rashiq BM BS MS FRCPC ${ }^{2}$, \\ Igor Sobolev MD FRCPC ${ }^{2}$, Donald W Morrish MD PhD FRCPC ${ }^{1}$
}

D Wong, D Gray, M Simmonds, S Rashiq, I Sobolev, DW Morrish. Opioid analgesics suppress male gonadal function, but opioid use in men and women does not correlate with symptoms of sexual dysfunction. Pain Res Manage 2011;16(5):311-316.

BACKGROUND: Opioid analgesia impairs gonadal function in men and women, but the correlation with symptoms and hormonal measurements of hypogonadism is not well established.

OBJECTIVE: To determine the frequency of impaired gonadal function in men and women using opioids for chronic pain, and to determine the correlation of symptoms with hormonal measurements of gonadal function.

METHODS: A prospective study of patients attending a multidisciplinary pain clinic was conducted. A total of 65 women (47 opioid users and 18 nonopioid analgesic controls) and 32 men ( 26 opioid users and six controls) were enrolled. Histories of sexual dysfunction and hormonal testing (men: total testosterone [TT], free testosterone [FT], prolactin and luteinizing hormone; women: FT, TT, prolactin, dehydroepiandrosterone sulphate, sex hormone-binding globulin, progesterone, luteinizing hormone and follicle-stimulating hormone, and estradiol) were obtained.

RESULTS: In men, a low FT level was more common in opioid users (20/26; $\mathrm{P}=0.04)$. In men with abnormal hormone levels, there was no difference in the frequency of sexual dysfunction compared with men with normal hormone levels, and no difference in the frequency of opioid versus nonopioid use. In women, opioid users had lower FT levels $(\mathrm{P}=0.02)$. Low dehydroepiandrosterone sulphate was more frequent in women on opioids $(\mathrm{P}=0.03)$ in the menopausal group only $(\mathrm{P}=0.046)$. Premenopausal women taking opioids more frequently had a low TT level $(\mathrm{P}=0.03)$. The frequency of female sexual dysfunction was the same in opioid users (32/47) and controls $(13 / 18 ; \mathrm{P}=0.75)$, and also did not relate to any hormone abnormality.

DISCUSSION: Men taking opioids had lower FT and higher prolactin levels, and women taking opioids had lower FT levels. Frequency of sexual dysfunction did not correlate with hormone levels in either men or women taking opioids.

CONCLUSION: Opioids frequently cause low FT levels in men, but there is no relationship between abnormal hormone levels and symptoms of sexual dysfunction. Therefore, all men should be screened for low FT levels. Women on opioids had lower FT levels, but this did not correlate with sexual dysfunction symptoms. Therefore, measurements of FT or other hormones were not considered to be useful in women.

Key Words: Gonadal dysfunction; Opioid analgesia; Pain syndromes; Sexual functioning

$\mathrm{C}$ hronic noncancer pain $(\mathrm{CNCP})$ is a serious societal problem affecting $25 \%$ of the American and $15 \%$ to $24 \%$ of the Canadian population $(1-3)$. In recent years, there has been an increasing trend towards the use of sustained-action opioids in the treatment of CNCP $(4,5)$. Although effective, opioids have gradually been recognized to have deleterious endocrine side effects, particularly of the reproductive system (6). Human and animal data indicate that opioids suppress luteinizing hormone-releasing hormone and gonadotropin secretion, leading to

\section{Les analgésiques opioïdes suppriment la fonction gonadique des hommes, mais l'utilisation d'opioïdes chez les hommes et les femmes n'est pas corrélée avec des symptômes de dysfonction sexuelle} des hommes et des femmes, mais sa corrélation avec les symptômes et les mesures hormonales d'hypogonadisme n'est pas bien établie.

OBJECTIF : Déterminer la fréquence d'atteinte de la fonction gonadique chez les hommes et les femmes qui utilisent des opioïdes pour soigner des douleurs chroniques, ainsi que la corrélation des symptômes avec les mesures hormonales de la fonction gonadique.

MÉTHODOLOGIE : Les chercheurs ont procédé à une étude prospective de patients qui fréquentaient une clinique de douleur multidisciplinaire. Au total, 65 femmes ( 47 utilisatrices d'opioïdes et 18 sujets témoins prenant des analgésiques non opioïdes) et 32 hommes ( 26 utilisateurs d'opiö̈des et six sujets témoins) y ont participé. Les chercheurs ont obtenu les antécédents de dysfonction sexuelle et de tests hormonaux (hommes : testostérone totale [TT], testostérone libre [TL], prolactine et hormone lutéinisante; homme : TL, TT, prolactine, sulfate de déhydroépiandrostérone, globuline liant les hormones sexuelles, progestérone, hormone lutéinisante et hormone folliculostimulante, œestradiol).

RÉSULTATS : Chez les hommes, un faible taux de TL était plus courant chez les utilisateurs d'opioïdes (20 sur $26 ; \mathrm{P}=0,04)$. On ne constatait aucune différence de fréquence de dysfonction sexuelle entre les hommes dont les taux hormonaux étaient anormaux et ceux dont les taux hormonaux étaient normaux, et aucune différence dans la fréquence d'utilisation d'opioïdes et de produits non opioïdes. Chez les femmes, les utilisatrices d'opioïdes présentaient des taux plus faibles de TL $(P=0,02)$. Le sulfate de déhydroépiandrostérone était souvent plus faible chez les femmes qui prenaient des opioïdes $(\mathrm{P}=0,03)$ du groupe seulement ménopausé $(\mathrm{P}=0,046)$. Les femmes préménopausées qui prenaient des opioïdes présentaient plus souvent un faible taux de TT $(\mathrm{P}=0,03)$. La fréquence de dysfonction sexuelle chez les femmes était la même chez les utilisatrices d'opioïdes (32 sur 47) que chez les sujets témoins (13 sur $18 ; \mathrm{P}=0,75)$ et n'était pas liée à une anomalie hormonale.

EXPOSÉ : Les hommes qui prenaient des opioïdes présentaient des taux de TL plus faibles et de prolactine plus élevés, et les femmes qui prenaient des opioïdes présentaient des taux de TL plus faibles. La fréquence de dysfonction sexuelle n'était pas corrélée avec les taux d'hormones des hommes ou des femmes qui prenaient des opioïdes.

CONCLUSION : Les opioïdes sont souvent responsables de faibles taux de TL chez les hommes, mais il n'y a pas de lien entre des taux hormonaux anormaux et les symptômes de dysfonction sexuelle.Par conséquent, tous les hommes devraient subir un dépistage de faibles taux de TL. Les femmes qui prennent des opioïdes présentaient des taux de TL plus faibles, qui n'étaient pas corrélés par des symptômes de dysfonction sexuelle. Par conséquent, les mesures de TL ou d'autres hormones n'étaient pas considérées comme utiles chez les femmes.

decreased testosterone levels and abnormal menstrual function (6-8). Some data in animals suggest that opioids may also directly suppress testicular function (7). This syndrome has been labelled as opioidinduced androgen deficiency $(4,9)$. The number of patients with this syndrome has been estimated at 229,000 to $5,000,000$ in the United States, and approximately 154,000 in Canada (9).

The consequences of gonadal dysfunction are significant, including symptoms of diminished libido, erectile dysfunction (ED), depression,

${ }^{1}$ Department of Medicine; ${ }^{2}$ Department of Anesthesiology, University of Alberta, Edmonton, Alberta

Correspondence: Dr Donald W Morrish, 362 Heritage Medical Research Centre, University of Alberta, Edmonton, Alberta T6G 2 S2.

Telephone 780-407-3636, fax 780-407-6702, e-mail dmorrish@ualberta.ca 
fatigue, hot flashes, mild anemia, osteoporosis and sarcopenia in men (10), and amenorrhea, oligomenorrhea, sexual dysfunction, fatigue, depression and osteoporosis in women.

Although most studies demonstrate suppression of testosterone in men $(4,11,12)$, sexual dysfunction in men and women has been inconsistently studied $(11,13,14)$. It is also unclear whether sexual dysfunction in those consuming chronic opiates for CNCP is entirely due to hypogonadism or whether the symptoms are secondary to the pain syndrome itself (14).

The goals of the present observational study were, therefore, to compare the incidence of gonadal and sexual dysfunction in CNCP between those treated with opioids and those treated without them, to determine the incidence of hormonal and sexual dysfunction in both groups and whether sexual dysfunction could be correlated with gonadal hormone deficiency, and to determine whether opioids display a dose-related association with gonadal dysfunction.

\section{METHODS}

\section{Subjects}

The study was approved by the Health Research Ethics Board at the University of Alberta (Edmonton). Participants were randomly selected from consenting patients visiting the Multidisciplinary Pain Centre (a specialist referral clinic for CNCP) at the University of Alberta Hospital between June 2008 and February 2009. All patients visiting this clinic had experienced chronic pain for more than six months. The study population was a convenience sample. A total of 65 women and 32 men consented to participation in the study. Patients who were clinically depressed, had alcoholism, had another major medical illness, were using testosterone (men), were using oral contraception or menopausal hormone replacement (women), or were using illicit drugs chronically were excluded.

\section{Procedure}

All patients interviewed were asked a set of questions pertaining to their general health and sexual function. The questions consisted of the patient's age, diagnosis of their pain condition, comorbidities, current medication, depression or experiences of depressive symptoms, and nicotine, alcohol and cannabis consumption.

For questions regarding sexual function, women were asked whether they currently had menstrual abnormalities (amenorrhea, oligomenorrhea or early menopause), whereas men were asked whether they experienced any form of ED. Both men and women were also asked to rate their sexual desire using a simple classification of "normal or decreased" compared with when they were not taking any narcotics or when they were pain free (if they had never consumed narcotics). Sexual dysfunction was defined as men or women who had poor sexual desire, menstrual abnormalities or ED. Women were defined as menopausal if they had either natural menopause, at least one year of absent menses or bilateral oophorectomy. Women were considered to be nonmenopausal if they had regular menses, irregular menses, hysterectomy or hysterectomy with unilateral oophorectomy.

Laboratory measurements consisted of serum prolactin, total testosterone (TT) and free testosterone (FT) in both men and women. Additionally, dehydroepiandrosterone sulphate (DHEAS), sex hormone-binding globulin (SHBG), luteinizing hormone (LH), follicle-stimulating hormone, progesterone and estradiol were measured in women, and LH was measured in men. Testosterone laboratory reference ranges for morning or afternoon were used depending on sample collection time.

\section{Data and statistical analysis}

The following statistical programs were used for data analysis: Microsoft Excel 2008 (Microsoft Corporation, USA), StatPlus:mac LE 2009 (AnalystSoft Inc, USA) and ChiTest Calculator (www.physics. csbsju.edu/stats/contingency_NROW_NCOLUMN_form.html).

For comparison, all oral opioid doses were converted to daily oral morphine-equivalent doses. The following were considered to be equivalent: morphine sulphate $30 \mathrm{mg}$, codeine sulphate $240 \mathrm{mg}$, oxycodone $20 \mathrm{mg}$, hydromorphone $6 \mathrm{mg}$, methadone $3 \mathrm{mg}$, meperidine $240 \mathrm{mg}$ and tramadol $240 \mathrm{mg}$. Fentanyl patches of $25 \mu \mathrm{g} / \mathrm{h}$ were considered to be equivalent to $90 \mathrm{mg}$ of daily oral morphine (15).

Linear regression analyses were performed on scatterplots of oral morphine-equivalent doses and corresponding hormone levels. Because data were not normally distributed, analysis of log-transformed data was also used. Two-way ANOVA was used to determine the difference in hormone levels. $\chi^{2}$ analysis was used to compare the incidence of abnormal hormone levels or sexual dysfunction among subject groups, and of correlations on regression analysis. Patients were considered to have abnormal hormone levels if their values fell outside of the laboratory normal reference ranges for each assay. Values were considered to be statistically significant at $\mathrm{P}<0.05$.

\section{RESULTS}

A total of 65 women (47 taking opioids) and 32 men (26 taking opioids) participated in the study. Subject demographic characteristics are shown in Table 1. Causes of the patients' pain syndromes were similar in all groups. The most common cause was degenerative changes involving osteoarthritis or intervertebral disc disease.

\section{Men}

Prolactin levels were significantly increased in male opioid users compared with controls (Table 2A), but no dose relationships were found between opioid dose and plasma levels of prolactin (Figure 1), TT or LH ( $\mathrm{P}>0.05$, data not shown) either using untransformed or log-transformed data. However, using log transformation of data, FT level showed a significant inverse relationship with morphine dose (Figure 1, middle panel). No other hormones showed a difference between these two groups. There were too few patients in separate groups using long- or short-acting opioids for comparison analysis of relationships to oral morphine-equivalent dose. Increased prolactin was present in the opioid users regardless of whether ED or desire was normal or abnormal (normal desire: control $5.5 \pm 0.4 \mu \mathrm{g} / \mathrm{L}$, opioid $12.7 \pm 2.6 \mu \mathrm{g} / \mathrm{L}, \mathrm{P}=0.03$; decreased desire: control 5.6 $\pm 0.7 \mu \mathrm{g} / \mathrm{L}$, opioid $9.8 \pm 1.3 \mu \mathrm{g} / \mathrm{L}, \mathrm{P}=0.01)$. Other hormones showed no differences between groups (data not shown).

A low FT level was more common in opioid users (Table 3A), but frequencies of abnormal TT, prolactin and LH levels compared with laboratory reference ranges were not different between these groups.

The incidence of sexual dysfunction (decreased desire, ED or both) was equally present in opioid users and nonopioid analgesic users (Table 4A). There was no association between low FT, low TT or high prolactin levels and decreased desire and/or ED (Table 5). Men with either or both decreased sexual desire and ED had lower FT levels regardless of whether they were on opioids (sexual function normal: $32.3 \pm 3.7 \mathrm{pmol} / \mathrm{L}$; abnormal sexual function: $17.8 \pm 3.5 \mathrm{pmol} / \mathrm{L}$, $\mathrm{P}=0.01)$.

\section{Women}

Significantly lower FT levels, but no other hormone differences, were found in women consuming opioids compared with controls (Table 2B). No significant associations between opioid dose and LH, DHEAS, TT or FT levels were found for female opioid users (Figure 1) based on either untransformed or log-transformed data (data not shown).

Female opioid users more frequently had decreased DHEAS levels compared with the control group (Table 3B). This was likely due to a preponderance of a low DHEAS level in menopausal women taking opioids (control: 0/8, opioid: 6/16; $\mathrm{P}=0.046$ ). This effect was not observed in premenopausal women (control: $1 / 10$, opioid: 9/31; $\mathrm{P}=0.22$ ).

No significant difference in frequency of sexual dysfunction was found among female opioid users compared with controls (Table 4B). There was no difference in the incidence of decreased sexual desire among menopausal or premenopausal women treated with opioids or nonopioid analgesics (Table 4B). However, premenopausal women with decreased sexual desire who were treated with opioids more frequently had low TT levels compared with controls (control: 0/5, 
TABLE 1A

Demographics of men

\begin{tabular}{|c|c|c|}
\hline & $\begin{array}{c}\text { Control } \\
\text { patients } \\
(n=6)\end{array}$ & $\begin{array}{c}\text { Opioid } \\
\text { patients } \\
(n=26)\end{array}$ \\
\hline Average age (range) & $52(36-70)$ & $55(29-77)$ \\
\hline Smokers, current & $0(0)$ & $10(38.5)$ \\
\hline Cannibis use & $0(0)$ & $4(15.4)$ \\
\hline \multicolumn{3}{|l|}{ Duration of opioid use, years } \\
\hline$<1$ & - & $9(34.6)$ \\
\hline $1-5$ & - & $8(30.8)$ \\
\hline$>5$ & - & $9(34.6)$ \\
\hline \multicolumn{3}{|c|}{ Daily opioid use (oral morphine equivalents), mg/day } \\
\hline $0-24$ & - & $3(11.5)$ \\
\hline $25-200$ & - & $17(65.4)$ \\
\hline$>200$ & - & $6(23.1)$ \\
\hline \multicolumn{3}{|l|}{ Sexual function } \\
\hline Decreased sexual desire & $4(66.6)$ & $18(69.2)$ \\
\hline Erectile dysfunction & $4(66.6)$ & $15(57.7)$ \\
\hline Depression or depressive symptoms & $2(33.3)$ & $17(65.4)$ \\
\hline \multicolumn{3}{|l|}{ Diagnosis of pain condition } \\
\hline Degenerative (arthritic, disk disease) & $3(50.0)$ & $12(46.2)$ \\
\hline Peripheral neuropathy & $0(0)$ & $1(3.8)$ \\
\hline Trauma & $0(0)$ & $2(7.7)$ \\
\hline Postsurgical & $0(0)$ & $3(11.5)$ \\
\hline Headaches & $1(16.7)$ & $1(3.8)$ \\
\hline $\begin{array}{l}\text { Postherpetic neuralgia, pancreatitis, cancer } \\
\text { (1 each) }\end{array}$ & $0(0)$ & $3(11.5)$ \\
\hline Unknown etiology & $2(33.3)$ & $4(15.4)$ \\
\hline \multicolumn{3}{|l|}{$\begin{array}{l}\text { TABLE 1B } \\
\text { Demographics of women }\end{array}$} \\
\hline & $\begin{array}{c}\text { Control } \\
\text { patients } \\
(n=18)\end{array}$ & $\begin{array}{c}\text { Opioid } \\
\text { patients } \\
(n=47)\end{array}$ \\
\hline Average age (range) & $55(25-84)$ & $53(28-83)$ \\
\hline Smokers, current & $4(22.2)$ & $18(38.3)$ \\
\hline Cannibis use & $0(0)$ & $4(8.5)$ \\
\hline \multicolumn{3}{|l|}{ Duration of opioid use, years } \\
\hline$<1$ & - & $16(34.0)$ \\
\hline $1-5$ & - & $26(55.3)$ \\
\hline$>5$ & - & $5(10.6)$ \\
\hline \multicolumn{3}{|c|}{ Daily opioid use (oral morphine equivalents), mg/day } \\
\hline $0-24$ & - & $15(31.9)$ \\
\hline $25-200$ & - & $23(48.9)$ \\
\hline$>200$ & - & $9(19.1)$ \\
\hline \multicolumn{3}{|l|}{ Sexual function } \\
\hline Decreased sexual desire & $13(72.2)$ & $32(68.1)$ \\
\hline Regular menses & $4(22.2)$ & $8(17.0)$ \\
\hline Absent menses & $1(5.6)$ & $6(12.8)$ \\
\hline Menopause & $4(22.2)$ & $10(21.3)$ \\
\hline Hysterectomy without oophorectomy & $3(16.7)$ & 9 (19.1) \\
\hline Hysterectomy with unilateral oophorectomy & 2 (11.1) & $8(17.0)$ \\
\hline Hysterectomy with bilateral oophorectomy & $4(22.2)$ & $6(12.8)$ \\
\hline Depression or depressive symptoms & $12(66.7)$ & $37(78.7)$ \\
\hline \multicolumn{3}{|l|}{ Diagnosis of pain condition } \\
\hline Degenerative (arthritis, disk disease) & $9(50.0)$ & $28(59.6)$ \\
\hline Peripheral neuropathy & 2 (11.1) & $1(2.1)$ \\
\hline Trauma & $1(5.6)$ & $4(8.5)$ \\
\hline Postsurgical & $3(16.7)$ & $3(6.4)$ \\
\hline Headaches & $1(5.6)$ & $2(4.3)$ \\
\hline $\begin{array}{l}\text { Inflammatory (polymyositis, scleroderma, } \\
\text { Wegener's granulomatosis, postherpetic } \\
\text { neuralgia, unspecified) (1 each) }\end{array}$ & $0(0)$ & $6(12.8)$ \\
\hline Fibromyalgia & $0(0)$ & $1(2.1)$ \\
\hline Phantom pain & $0(0)$ & $1(2.1)$ \\
\hline Unknown etiology & $2(11.1)$ & $1(2.1)$ \\
\hline
\end{tabular}

Data presented as $n$ (\%) unless otherwise indicated
TABLE 2A

Hormone values in men

\begin{tabular}{lrrl}
\hline & Control & Opioid use & \multicolumn{1}{c}{$\mathbf{P}$} \\
\hline Free testosterone, pmol/L & $30.2 \pm 5.0$ & $20.2 \pm 2.6$ & 0.12 \\
Total testosterone, nmol/L & $10.7 \pm 2.1$ & $8.6 \pm 0.9$ & 0.40 \\
Prolactin, $\mu \mathrm{g} / \mathrm{L}$ & $5.6 \pm 0.5$ & $10.7 \pm 1.2$ & 0.0006 \\
Luteinizing hormone, U/L & $5.3 \pm 0.6$ & $4.8 \pm 0.6$ & 0.11
\end{tabular}

TABLE 2B

Hormone values in women

\begin{tabular}{lccc}
\hline & Control & Opioid use & P \\
\hline Free testosterone, pmol/L & $2.3 \pm 0.2$ & $1.3 \pm 0.1$ & 0.02 \\
Total testosterone, nmol/L & $1.2 \pm 0.1$ & $0.9 \pm 0.1$ & 0.09 \\
Prolactin, $\mu \mathrm{g} / \mathrm{L}$ & $14.9 \pm 2.2$ & $12.2 \pm 2.2$ & 0.61 \\
DHEAS, U/L & $2.7 \pm 0.2$ & $1.7 \pm 0.3$ & 0.11 \\
SHBG, nmol/L & $52.5 \pm 6.7$ & $65.6 \pm 8.5$ & 0.34 \\
T/SHBG & $0.015 \pm 0.01$ & $0.023 \pm 0.003$ & 0.16 \\
Progesterone, nmol/L & $3.74 \pm 0.9$ & $2.8 \pm 1.2$ & 0.70 \\
Luteinizing hormone, U/L & $15.3 \pm 2.1$ & $18.8 \pm 3.3$ & 0.75 \\
FSH, U/L & $30.8 \pm 6.0$ & $33.7 \pm 5.5$ & 0.94 \\
Estradiol, pmol/L & $145.3 \pm 25.0$ & $154.6 \pm 36.8$ & 0.74
\end{tabular}

Data presented as mean \pm SEM. DHEAS Dehydroepiandrosterone sulphate; FSH Follicle-stimulating hormone; SHBG Sex hormone-binding globulin; T Testosterone

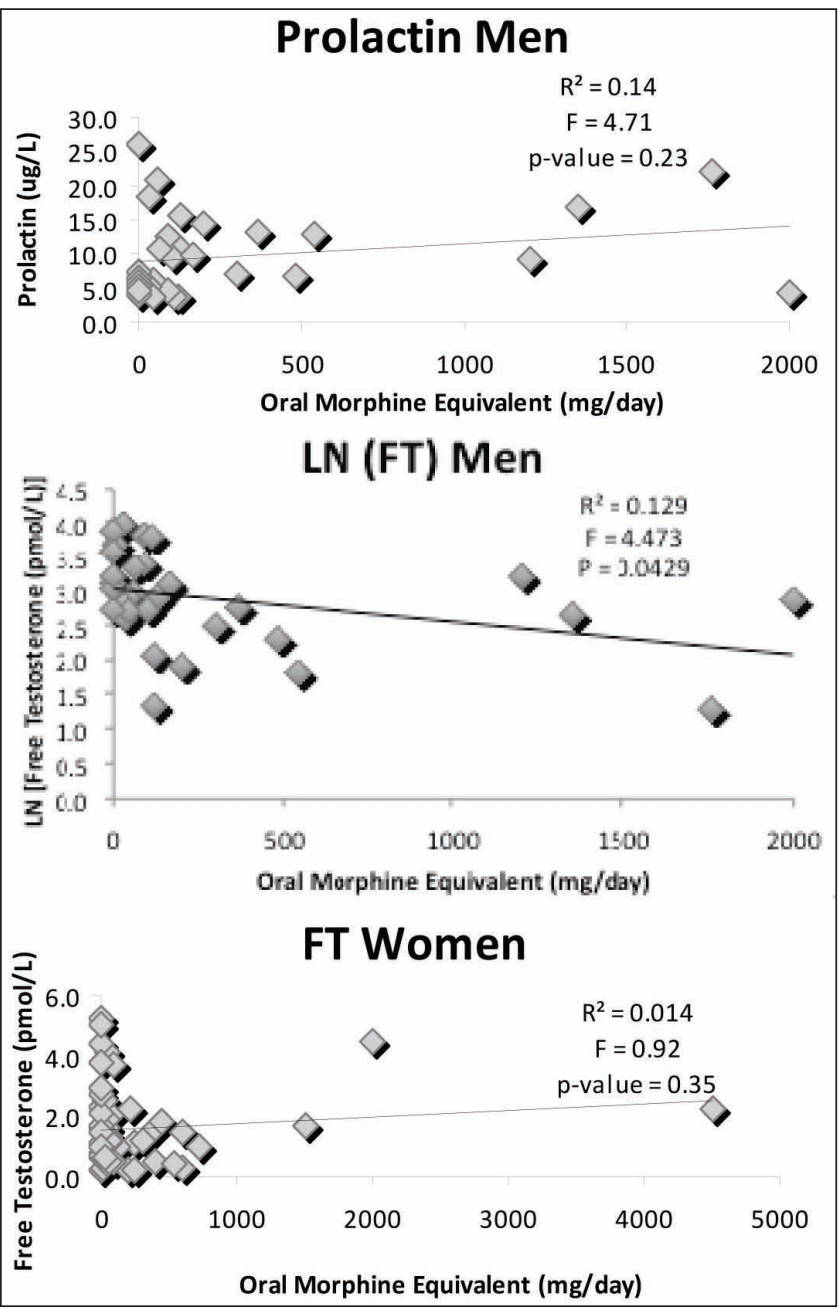

Figure 1) Dose-response effect of opioids on hormone levels. Top panel Prolactin in men. Middle panel LN free testosterone (FT) in men. Bottom panel FT in women. Only LN FT in men showed a significant relationship with morphine equivalent dose 
TABLE 3A

Number of men with abnormal hormone levels

\begin{tabular}{lcccc}
\hline & Control & Opioid use & $\boldsymbol{\chi}^{2}$ & $\mathbf{P}$ \\
\hline Low FT & $2 / 6$ & $20 / 26$ & 4.31 & 0.04 \\
Low TT & $3 / 6$ & $16 / 25$ & 0.40 & 0.53 \\
High prolactin & $0 / 6$ & $2 / 26$ & 0.49 & 0.48 \\
High LH & $0 / 6$ & $1 / 26$ & 0.24 & 0.63
\end{tabular}

TABLE 3B

Number of women with abnormal hormone levels

\begin{tabular}{lcccc}
\hline & Control & Opioid use & $\chi^{2}$ & $\mathbf{P}$ \\
\hline Low FT & $0 / 17$ & $6 / 46$ & 2.45 & 0.12 \\
Low TT & $3 / 16$ & $16 / 44$ & 1.68 & 0.20 \\
High prolactin & $2 / 18$ & $4 / 47$ & 0.11 & 0.75 \\
Low DHEAS & $1 / 18$ & $15 / 47$ & 4.87 & 0.03 \\
High SHBG & $1 / 10$ & $2 / 36$ & 0.25 & 0.62 \\
Low T/SHBG & $1 / 8$ & $12 / 34$ & 1.57 & 0.21 \\
\hline
\end{tabular}

Data presented as $n / N$. DHEAS Dehydroepiandrosterone sulphate; FT Free testosterone; LH Luteinizing hormone; SHBG Sex hormone-binding globulin;

$T$ Testosterone; TT Total testosterone

TABLE 4A

Number of men with sexual dysfunction who were treated with either opioid or nonopioid analgesics

\begin{tabular}{lcccc}
\hline & Control & Opioid use & $\chi^{2}$ & $\mathbf{P}$ \\
\hline Decreased desire & $4 / 6$ & $18 / 26$ & 0.01 & 0.90 \\
Erectile dysfunction & $4 / 6$ & $15 / 26$ & 0.16 & 0.69 \\
Both & $3 / 6$ & $12 / 26$ & 0.00 & 0.87 \\
Either & $5 / 6$ & $21 / 26$ & 0.02 & 0.89
\end{tabular}

TABLE 4B

Number of women with sexual dysfunction who were treated with either opioid or nonopioid analgesics

\begin{tabular}{lcccc}
\hline & Control & Opioid use & $\chi^{2}$ & $\mathbf{P}$ \\
\hline All women & & & & \\
Decreased desire & $13 / 18$ & $32 / 47$ & 0.11 & 0.75 \\
Menstrual abnormalities & $1 / 5$ & $4 / 12$ & 0.30 & 0.58 \\
Both & $0 / 5$ & $4 / 12$ & 2.18 & 0.14 \\
Either & $4 / 5$ & $9 / 12$ & 0.05 & 0.83 \\
Menopausal women & & & & \\
$\quad$ Decreased desire & $6 / 8$ & $13 / 16$ & 0.13 & 0.72 \\
Nonmenopausal women & & & & \\
$\quad$ Decreased desire & $7 / 10$ & $19 / 31$ & 0.25 & 0.62 \\
\hline
\end{tabular}

Data presented as $n / N$

opioid: 8/16; $\mathrm{P}=0.04$ ). No other hormones (FT, prolactin, DHEAS, SHBG, TT, T/SHBG) showed significant differences in frequency of abnormality among menopausal women suffering from decreased sexual desire (Table 6) or with abnormal menses (data not shown) treated with either opioids or nonopioid analgesics. Also, no significant differences in frequency of abnormal hormones were found for menopausal or premenopausal women with normal sexual desire treated with either opioids or control (Table 7). Hormone levels and sexual desire in control and opioid groups according to menopausal status are given separately in Table 8. Only TT was found to be lower in premenopausal women with decreased desire. However, because of the small numbers of patients in groups, these results must be interpreted with caution.

\section{DISCUSSION}

Among our male subjects, we found a higher frequency of low FT and increased prolactin in opioid users, as has been previously reported in oral opioid users and heroin addicts $(2,4,11,14,16,17)$. However, we found no significant difference in the frequency of sexual dysfunction
TABLE 5

Number of men with abnormal hormones experiencing normal or decreased sexual desire, and normal or abnormal erectile function

\begin{tabular}{|c|c|c|c|c|}
\hline & \multicolumn{2}{|c|}{ Sexual desire } & \multirow[b]{2}{*}{$\chi^{2}$} & \multirow[b]{2}{*}{$\mathbf{P}$} \\
\hline & Normal & Decreased & & \\
\hline Low FT & $5 / 10$ & $17 / 22$ & 2.38 & 0.12 \\
\hline Low TT & $5 / 9$ & $14 / 22$ & 0.18 & 0.68 \\
\hline High prolactin & $1 / 10$ & $1 / 22$ & 0.35 & 0.56 \\
\hline \multirow[t]{3}{*}{ High LH } & $0 / 10$ & $1 / 22$ & 0.47 & 0.49 \\
\hline & \multicolumn{2}{|c|}{ Erectile function } & & \\
\hline & Normal & Dysfunction & $\chi^{2}$ & $\mathbf{P}$ \\
\hline Low FT & $8 / 13$ & $14 / 19$ & 0.53 & 0.47 \\
\hline Low TT & $6 / 12$ & $13 / 19$ & 1.05 & 0.31 \\
\hline High prolactin & $1 / 13$ & $1 / 19$ & 0.08 & 0.78 \\
\hline High LH & $1 / 13$ & 0/19 & 1.51 & 0.22 \\
\hline
\end{tabular}

Data presented as n/N. FT Free testosterone; LH Luteinizing hormone; TT Total testosterone

TABLE 6A

Hormone levels in women with normal or decreased sexual desire

\begin{tabular}{lccc}
\hline & \multicolumn{2}{c}{ Sexual desire } & \\
\cline { 2 - 3 } Hormone & Normal & Decreased & P \\
\hline FT, pmol/L & $1.7 \pm 0.3$ & $1.5 \pm 0.1$ & 0.58 \\
TT, nmol/L & $1.1 \pm 0.1$ & $0.93 \pm 0.03$ & 0.38 \\
Prolactin, $\mu \mathrm{g} / \mathrm{L}$ & $16.7 \pm 4.6$ & $11.3 \pm 0.6$ & 0.30 \\
DHEAS, U/L & $2.6 \pm 0.6$ & $1.7 \pm 0.1$ & 0.19 \\
SHBG, nmol/L & $56.2 \pm 7.9$ & $65.7 \pm 3.6$ & 0.45 \\
T/SHBG & $0.032 \pm 0.08$ & $0.024 \pm 0.001$ & 0.35 \\
Progesterone, nmol/L & $2.3 \pm 0.8$ & $3.2 \pm 0.5$ & 0.56 \\
LH, U/L & $22.9 \pm 5.1$ & $16.5 \pm 1.1$ & 0.29 \\
FSH, U/L & $43.0 \pm 9.8$ & $29.9 \pm 1.9$ & 0.26 \\
Estradiol, pmol/L & $134.0 \pm 36.8$ & $157.4 \pm 14.2$ & 0.67
\end{tabular}

Data presented as mean \pm SEM

TABLE 6B

Number of women with abnormal hormones with normal or decreased sexual desire

\begin{tabular}{lcccc}
\hline & \multicolumn{3}{c}{ Sexual desire } & \\
\cline { 2 - 4 } Hormone & Normal & Decreased & $\chi^{2}$ & $\mathbf{P}$ \\
\hline Low FT & $2 / 20$ & $4 / 43$ & 0.08 & 0.93 \\
Low TT & $4 / 20$ & $15 / 40$ & 1.89 & 0.17 \\
High prolactin & $4 / 20$ & $2 / 45$ & 4.00 & 0.05 \\
Low DHEAS & $3 / 20$ & $13 / 45$ & 1.44 & 0.23 \\
High SHBG & $0 / 14$ & $2 / 32$ & 0.92 & 0.34 \\
Low T/SHBG & $2 / 14$ & $10 / 28$ & 2.10 & 0.15 \\
\hline
\end{tabular}

Data presented as $n / N$. DHEAS Dehydroepiandrosterone sulphate; FSH Follicle-stimulating hormone; FT Free testosterone; LH Luteinizing hormone; SHBG Sex hormone-binding globulin; T Testosterone; TT Total testosterone

among male opioid users and men treated with nonopioid analgesics. These data indicate that the chronic pain syndrome produces symptoms of sexual dysfunction similar to taking opioids. Other authors have also noted a high frequency of sexual function in nonopioid analgesic use (14). Therefore, clinical presentation cannot be taken as an indicator of whether true hypogonadism is present. Nonetheless, when sexual dysfunction was present in opioid or nonopioid analgesic users, we found that these subjects had lower FT levels.

We did demonstrate increased prolactin in opioid users compared with control nonopioid analgesic users, as has been reported in patients on methadone and in those who smoke opium $(4,14,16)$, 
but not previously reported in other oral opioid therapies. Only five of our patients were on methadone and their prolactin levels were not different from nonmethadone opioid users (methadone: $10.3 \pm 5.2 \mu \mathrm{g} / \mathrm{L}$; other opioid users: $10.8 \pm 6.6 \mu \mathrm{g} / \mathrm{L}$; P value nonsignificant). Because the prolactin levels were not increased above the laboratory reference upper limit, the increase would not otherwise be detected.

Altogether, these results indicate that opioids do reduce the plasma levels of FT and increase prolactin levels, and a correlation does exist between sexual dysfunction and low FT levels among men suffering from chronic pain. However, the results also suggest that chronic pain itself is frequently responsible for sexual dysfunction among our male subjects, and that opioids do not significantly increase the frequency of sexual function among men suffering from chronic pain. Daniell (4) found that sexual dysfunction was common (87\%) but the frequency of this in controls was not given.

Hence, although male hypogonadism is common, symptoms are not a reliable guide to its presence. We, therefore, recommend that all male patients have biochemical screening for hypogonadism. Correction of hypogonadism would be important to improve patient well-being and to treat possible secondary consequences such as osteoporosis.

Among our female subjects, we found no significant linear relationship between oral opioid dose and plasma hormone levels. Opioid users had significantly lower FT levels than controls, as has been reported by Daniell et al (12). Also, premenopausal (but not menopausal) opioid users had a higher frequency of low DHEAS levels compared with women in the control group, although the levels were not significantly different. As was observed for men, no significant difference in the incidence of sexual dysfunction was found among female opioid users and female subjects treated with nonopioid analgesics. Normal or abnormal sexual function (desire and menstrual function) also did not demonstrate any correlation with any abnormal hormone, with the exception of low TT levels being found to occur more frequently in women with abnormal menses (Tables 8 and 9).

In more recent studies in women, Daniell (9) found low DHEAS levels in $67 \%$ of opioid users, with concomitant normal adrenocorticotropic hormone levels, suggesting central suppression of the hypothalamic-pituitary-adrenal axis. We also found low DHEAS levels, but this appeared to only be in the menopausal group. Also, Daniell (9) has shown that testosterone, estradiol and DHEAS levels were $48 \%$ to $57 \%$ lower in opioid users. However, sexual desire was
TABLE 7

Hormone levels in women with normal and decreased sexual desire who were treated with opioids or nonopioid analgesics

\begin{tabular}{|c|c|c|c|}
\hline \multirow[b]{2}{*}{ Hormone } & \multicolumn{2}{|c|}{ Normal sexual desire } & \multirow[b]{2}{*}{$\mathbf{P}$} \\
\hline & Control & Opioid use & \\
\hline $\mathrm{FT}, \mathrm{pmol} / \mathrm{L}$ & $2.8 \pm 0.8$ & $1.33 \pm 0.23$ & 0.14 \\
\hline TT, nmol/L & $1.7 \pm 0.32$ & $0.88 \pm 0.12$ & 0.06 \\
\hline Prolactin, $\mu \mathrm{g} / \mathrm{L}$ & $31.6 \pm 15.0$ & $11.7 \pm 3.0$ & 0.26 \\
\hline DHEAS, U/L & $4.4 \pm 1.2$ & $2.0 \pm 0.7$ & 0.13 \\
\hline SHBG, nmol/L & $42.0 \pm 10.8$ & $61.9 \pm 9.9$ & 0.21 \\
\hline T/SHBG & $0.055 \pm 0.025$ & $0.023 \pm 0.004$ & 0.30 \\
\hline Progesterone, nmol/L & $3.2 \pm 1.7$ & $1.9 \pm 1.0$ & 0.55 \\
\hline $\mathrm{LH}, \mathrm{U} / \mathrm{L}$ & $20.0 \pm 6.9$ & $24.0 \pm 6.8$ & 0.69 \\
\hline FSH, U/L & $45.8 \pm 17.2$ & $41.8 \pm 12.5$ & 0.86 \\
\hline \multirow[t]{2}{*}{ Estradiol, pmol/L } & $109.3 \pm 34.4$ & $144 \pm 50$ & 0.58 \\
\hline & \multicolumn{2}{|c|}{ Decreased sexual desire } & \\
\hline Hormone & Control & Opioid users & $\mathbf{P}$ \\
\hline $\mathrm{FT}$, pmol/L & $2.1 \pm 0.2$ & $1.27 \pm 0.07$ & 0.10 \\
\hline TT, nmol/L & $1.0 \pm 0.1$ & $0.90 \pm 0.04$ & 0.60 \\
\hline Prolactin, $\mu \mathrm{g} / \mathrm{L}$ & $8.5 \pm 0.8$ & $12.5 \pm 1.0$ & 0.22 \\
\hline DHEAS, U/L & $2.1 \pm 0.3$ & $1.6 \pm 0.1$ & 0.37 \\
\hline SHBG, nmol/L & $59.5 \pm 13.4$ & $67.1 \pm 4.4$ & 0.71 \\
\hline T/SHBG & $0.03 \pm 0.01$ & $0.022 \pm 0.001$ & 0.43 \\
\hline Progesterone, nmol/L & $3.6 \pm 1.5$ & $3.1 \pm 0.7$ & 0.84 \\
\hline $\mathrm{LH}, \mathrm{U} / \mathrm{L}$ & $15.6 \pm 3.6$ & $16.7 \pm 1.5$ & 0.85 \\
\hline $\mathrm{FSH}, \mathrm{U} / \mathrm{L}$ & $28.1 \pm 9.8$ & $30.4 \pm 2.4$ & 0.88 \\
\hline Estradiol, pmol/L & $151.6 \pm 46.7$ & $159.1 \pm 19.8$ & 0.93 \\
\hline
\end{tabular}

Data presented as mean \pm SEM. DHEAS Dehydroepiandrosterone sulphate; FSH Follicle-stimulating hormone; FT Free testosterone; LH Luteinizing hormone; SHBG Sex hormone-binding globulin; T Testosterone; TT Total testosterone

not determined in these studies. In our studies, we found no relationships between sexual dysfunction and hormone levels.

Although these results indicate that opioids do affect FT levels among women suffering from chronic pain, no significant dose response was found between hormone levels and opioid dose. Our results also showed that opioids do not significantly increase the frequency of sexual dysfunction among women suffering from chronic

TABLE 8

Number of women with normal or decreased sexual desire and abnormal hormones who were treated with opioid or nonopioid analgesics

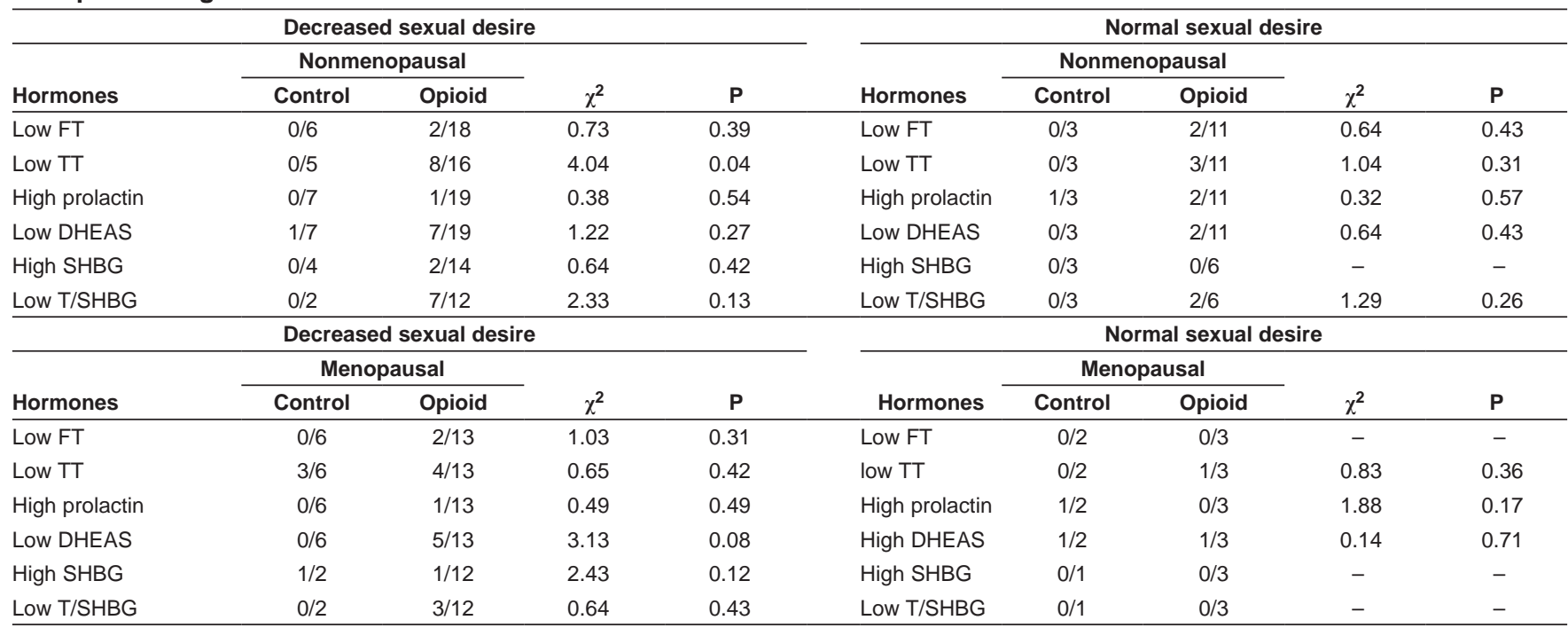

Data presented as n/N. DHEAS Dehydroepiandrosterone sulphate; FT Free testosterone; SHBG Sex hormone-binding globulin; T Testosterone; TT Total testosterone 
TABLE 9

Average hormone levels in women with normal or abnormal menses

\begin{tabular}{lccc}
\hline & \multicolumn{2}{c}{ Menstruation } & \\
\cline { 2 - 3 } Hormones & Normal & Abnormal & P \\
\hline FT, pmol/L & $1.4 \pm 0.2$ & $2.0 \pm 0.9$ & 0.53 \\
TT, nmol/L & $1.2 \pm 0.2$ & $0.96 \pm 0.49$ & 0.68 \\
Prolactin, $\mu \mathrm{g} / \mathrm{L}$ & $12.0 \pm 3.0$ & $10.1 \pm 2.2$ & 0.62 \\
DHEAS, U/L & $3.8 \pm 1.0$ & $2.6 \pm 0.8$ & 0.36 \\
SHBG, nmol/L & $87.4 \pm 28.0$ & $67.7 \pm 24.7$ & 0.61 \\
T/SHBG & $0.03 \pm 0.01$ & $0.05 \pm 0.04$ & 0.64 \\
Progesterone, nmol/L & $3.4 \pm 1.8$ & $5.6 \pm 1.8$ & 0.42 \\
LH, U/L & $6.3 \pm 1.3$ & $7.8 \pm 5.3$ & 0.80 \\
FSH, U/L & $8.5 \pm 3.1$ & $8.0 \pm 2.8$ & 0.91 \\
Estradiol, pmol/L & $264 \pm 117$ & $290 \pm 180$ & 0.91 \\
\hline
\end{tabular}

Data presented as mean \pm SEM. DHEAS Dehydroepiandrosterone sulphate; FSH Follicle-stimulating hormone; FT Free testosterone; LH Luteinizing hormone; SHBG Sex hormone-binding globulin; T Testosterone; TT Total testosterone

pain, which suggests that other factors are responsible for these symptoms. Opioid analgesics, chronic pain and depression were the most common characteristics among the women in the present study, which are also frequent causes of female sexual dysfunction.

The more frequent finding of low DHEAS levels in menopausal women may be due to lower hormone production in menopause rather than opioids. However, Daniell (9) attributed the decreased DHEAS level to opioid use, although that study did not specifically differentiate between menopausal and premenopausal subjects.

Androgen levels (TT, FT and DHEAS, but not SHBG) decrease in women with increasing age and after menopause (18). Guay et al (19) also demonstrated that women with sexual dysfunction have lower DHEAS, T and FT levels, although due to a small sample size, the level of statistical significance of these results must be interpreted with caution. We have also found lower DHEAS and FT levels, and similarly suggest caution in interpretation due to small sample sizes.

Because no correlation was found for women experiencing sexual dysfunction and low androgen levels, asking patients about their opioid consumption and sexual dysfunction is not an appropriate screening tool in predicting low androgen levels in women suffering from chronic pain.

In summary, our results confirm that opioid analgesics have a significant adverse effect on male testosterone levels. We were not able to confirm any hormonal associations with sexual dysfunction in women. Because sexual dysfunction was equally common in CNCP experienced by opioid and nonopioid users, a history of such dysfunction is not a sufficiently sensitive tool for determining hormonal status in either men or women. Laboratory measurement of male sex hormones in CNCP patients is, therefore, indicated because effective replacement therapy is available and would be expected to have beneficial effects on both sexual function and some aspects of nonsexual function (eg, muscle strength and bone density). However, because decreased hormone levels do not correlate with sexual dysfunction in women, it is unclear whether androgen replacement therapy would be beneficial in this chronic pain group. Other studies in non-narcotic-treated pain patients demonstrate the beneficial effects of androgen replacement on desire if low androgen levels are present (20).

Limitations of the present study include small numbers of patients in the male control group and in subgroups, and use of a simplified, nonvalidated questionnaire for sexual health due to subject compliance; the use of a simplified sexual health questionnaire may have introduced recall bias. Also, premenopausal female hormones were not measured at a defined phase of the menstrual cycle due to the necessity of obtaining testing when subjects were in the clinic due to compliance, which may have altered the results.

ACKNOWLEDGEMENTS: This study was supported by the Alberta Council of Professionals for Sexual Health.

\section{REFERENCES}

1. National Center for Health Statistics. Health, United States, 2006: With Chartbook on Trends in the Health of Americans. Hyattsville: NCHS, 2006:68-71. <www.222.cdc.gov/nchs/data/hus/ hus06.pdf $>$ (Accessed on July 5, 2010).

2. Gallagher RM, Rosenthal LJ. Chronic pain and opiates: Balancing pain control and risks of long-term opioid treatment. Arch Phys Med Rehabil 2008;89:S77-82.

3. Van Den Kerkhof EG, Hopman WM, Towheed TE, Anastassiades TP, Goldstein DH; Canadian Multicentre Osteoporosis Study Research Group. The impact of sampling and measurement on the prevalence of self-reported pain in Canada. Pain Res Manag 2003;8:157-63.

4. Daniell HW. Hypogonadism in men consuming sustained-action oral opioids. J Pain 2002;3:377-84.

5. Joranson DE, Ryan KM, Gilson AM, Dahl JL. Trends in medical use and abuse of opioid analgesics. JAMA 2000;283:1710-4.

6. Vuong C, Van Uum SHM, O'Dell LE, Lutfy K, Friedman TC. The effects of opioids and opioid analogs on animal and human endocrine systems. Endocr Rev 2010;31:98-132.

7. Adams ML, Sewing B, Forman JB, Meyer ER, Cicero TJ. Opioid-induced suppression of rat testicular function. J Pharmacol Exp Ther 1993;266:323-8.

8. Giri M, Kaufman JM. Opioidergic modulation of in vitro pulsatile gonadotropin-releasing hormone release from the isolated medial basal hypothalamus of the male guinea pig. Endocrinology 1994;135:2137-43.

9. Daniell HW. DHEAS deficiency during consumption of sustained-action prescribed opioid - evidence for opioid-induced inhibition of adrenal androgen production. J Pain 2006;7:901-7.

10. Fraser LA, Morrison D, Morley-Forster P, et al. Oral opioids for chronic non-cancer pain: Higher prevalence of hypogonadism in men than in woman. Exp Clin Endocrinol Diabetes 2009;117:38-43.

11. Azizi F, Vagenakis AG, Longcope C, Ingbar SH, Braverman LE. Decreased serum testosterone concentration in male heroin and methadone addicts. Steroids 1973;22:467-72.

12. Daniell HW. Opioid endocrinopathy in women consuming prescribed sustained-action opioids for control of non-malignant pain. J Pain 2008;9:28-36.

13. Rajagopal A, Vassilopoulou-Sellin R, Palmer HL, Kaur G, Bruera E. Hypogonadism and sexual dysfunction in male cancer survivors receiving chronic opioid therapy. J Pain Symptom Manag 2003;25:1055-61.

14. Pereira J, Bruera E. Alberta Hospice Palliative Care Resource Manual, 2nd edn. Edmonton: Alberta Cancer Board, 2001:1-88. $<$ www.palliative.org/PC/ClinicalInfo/ACB\%20PC\%20resource\%20 manual.pdf $>$ (Accessed on July 5, 2011).

15. Moshtaghi-Kashanian GR, Esmaeeli F, Dabiri S. Enhanced prolactin levels in opium smokers. Addict Biol 2005;10:345-9.

16. Rasheed A, Tareen IA. Effects of heroin on thyroid function, cortisol and testosterone level in addicts. Pol J Pharmacol 1995;47:441-4.

18. Guay A, Jacobson J, Talakoub L, Traish A, Quirk F, Spark R. Serum androgen levels in healthy premenopausal women with and without sexual dysfunction: Part A. Serum androgen levels in women aged 20-49 years with no complaints of sexual dysfunction. Int J Imp Res 2004;16:112-20.

19. Guay A, Jacobson J, Munarriz R, et al. Serum androgen levels in healthy premenopausal women with and without sexual dysfunction: Part B. Reduced serum androgen levels in healthy premenopausal women with complaints of sexual dysfunction. Int J Imp Res 2004;16:121-9.

20. Buster JE, Kingsberg SA, Aguirre O, et al. Testosterone patch for low sexual desire in surgically menopausal women: A randomized trial. Obstet Gyncol 2005;105:944-52. 


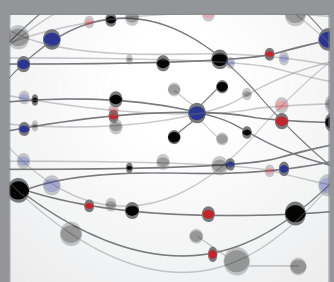

The Scientific World Journal
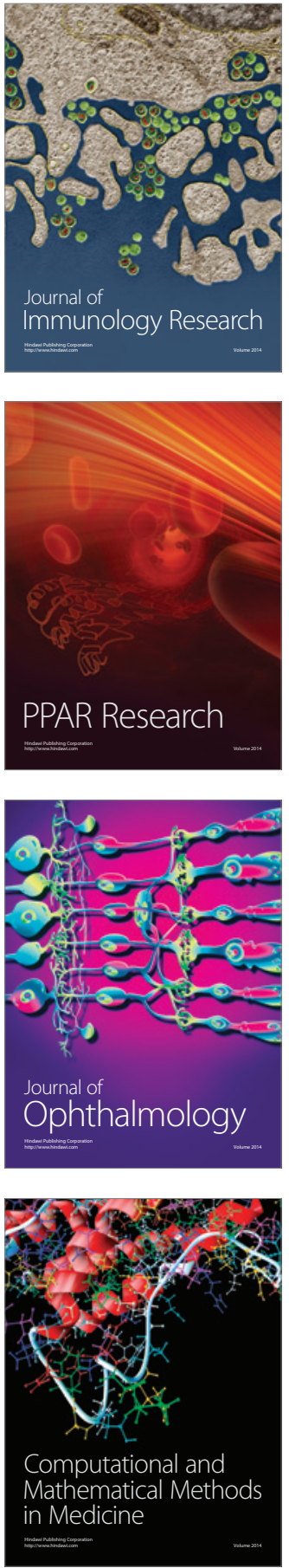

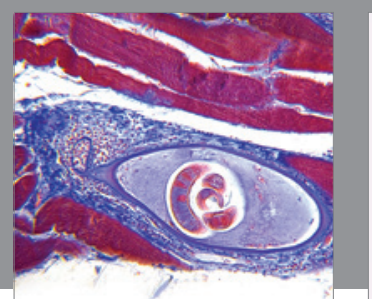

Gastroenterology Research and Practice

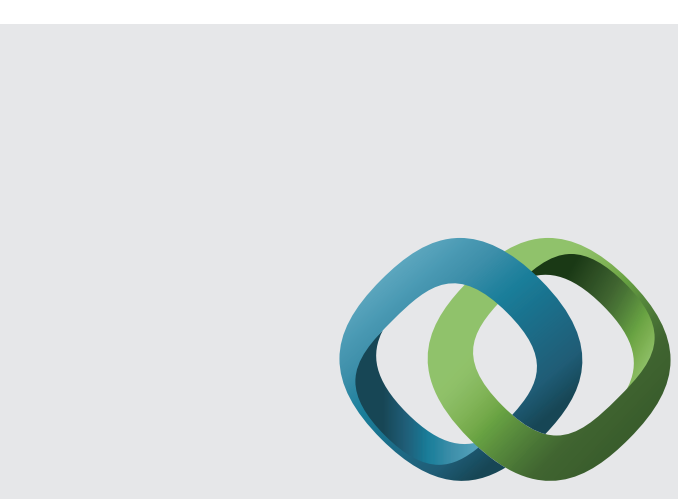

\section{Hindawi}

Submit your manuscripts at

http://www.hindawi.com
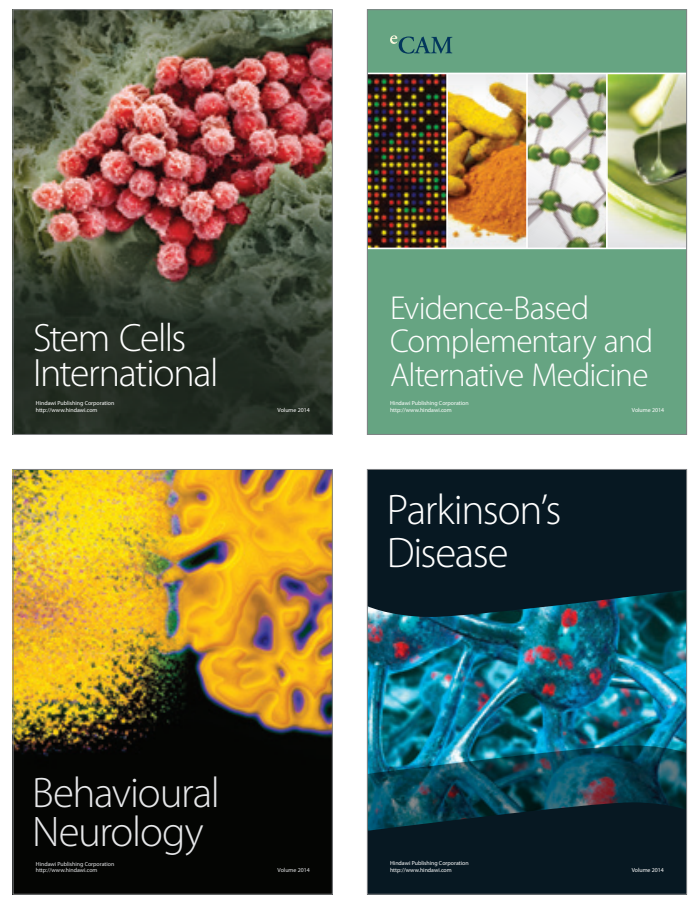
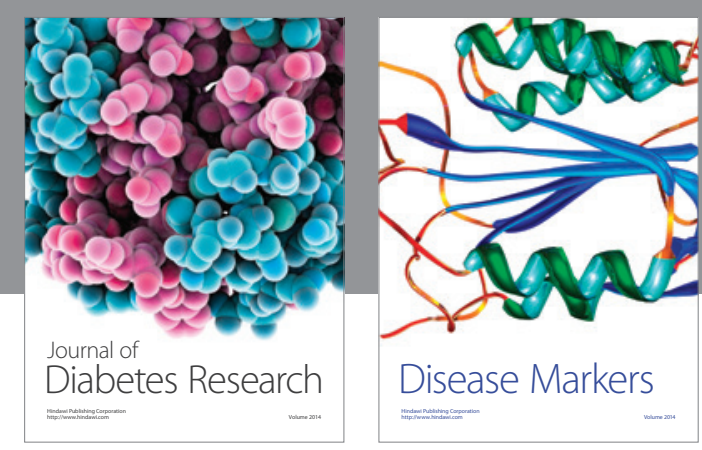

Disease Markers
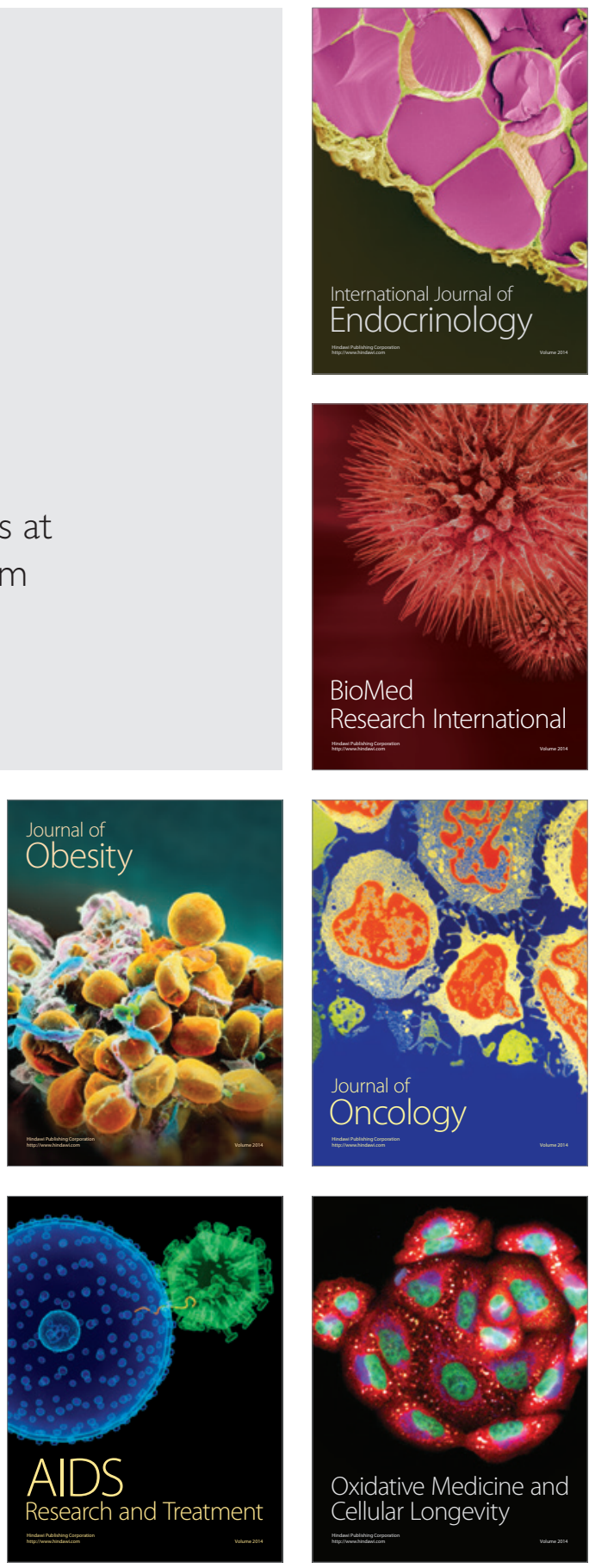